Brit. J. industr. Med., 1962, 19, 276.

\title{
TOXIC PROPERTIES OF DIALKYLNITROSAMINES AND SOME RELATED COMPOUNDS
}

\author{
BY \\ D. F. HEATH and P. N. MAGEE \\ From the Medical Research Council, Toxicology Research Unit, Medical Research \\ Council Laboratories, Woodmansterne Road, Carshalton, Surrey \\ (RECEIVED FOR PUBLICATION MAY 8, 1962)
}

\begin{abstract}
The title compounds, which have some commercial applications, are described, and their toxic action is reviewed. Most results refer to rats.

Their main acute effect is hepatic centrilobular necrosis, though lung lesions may appear. The compounds also induce tumours in liver, lung, and kidney. One, dimethylnitrosamine, has been shown to cause kidney tumours after a single dose. The necrotic and carcinogenic doses of the compounds are closely related.

The relation between structure and toxicity is discussed. Analogous formamides are much less toxic (the $\mathrm{LD}_{50}$ 's in rats by intraperitoneal injection of dimethyl- and diethyl-formamides are $3,800 \mathrm{mg} . / \mathrm{kg}$. and $1,740 \mathrm{mg} . / \mathrm{kg}$.) and they do not cause centrilobular necrosis or tumours.

Nitrosamines are oxidized in vivo and by liver preparations in vitro. Their toxic action is due to the release of powerful alkylating agents in the liver. They also inhibit protein synthesis and alkylate liver protein and ribonucleic acid. In all cases the effective agent appears to be a metabolite.

The possible hazard to man in the uses of these compounds is emphasized.
\end{abstract}

This paper is mainly a review, but it also includes observations which have not been published elsewhere. Some dialkylnitrosamines are valuable chemical intermediates or solvents, and their use as insecticides has been suggested (Reilly, 1961). Our aim is therefore to increase awareness of the hazards in their use, as well as to summarize the properties of a group of compounds of toxicological interest.

The dialkylnitrosamines have the structure; $R R^{\prime} \mathbf{N} \cdot N O$, where $R$ and $\mathbf{R}^{\prime}$ are alkyl groups. Closely related nitrosamines are also considered. These may contain substituents in the alkyl group, as in the 2-hydroxyethyl compounds (see Table 1); or one of the groups may be an aryl group, as in (methyl)(phenyl)nitrosamine; or the amino nitrogen may be in an aliphatic ring, as in N-nitrosomorpholine and N-nitrosopiperidine. Some of the corresponding dialkylformamides are also compared briefly. In these compounds a $\cdot \mathrm{CHO}$ group substitutes for the $\cdot \mathrm{NO}$ of the nitrosamines. Thus, dimethylformamide is $\left(\mathrm{CH}_{3}\right)_{2} \mathrm{~N} \cdot \mathrm{CHO}$

\section{Methods}

$\mathrm{LD}_{50}$ 's of the formamides were determined as described by Weil (1952) using solutions of the compounds in normal saline injected intraperitoneally. For the other compounds the original papers should be referred to.

\section{Physicochemical Properties}

The compounds are listed in Table 1, where some physical properties are also given. The simple dialkyl- and (alkyl)(aryl)-nitrosamines are all soluble in most organic solvents, and can be extracted from water by chloroform. The ease of extraction increases with the number of carbon atoms in the molecule in the usual way. Dimethylnitrosamine is miscible with water in all proportions. The rest have limited solubilities, depending on the shape and size of the alkyl groups. The distillation of aqueous solutions yields distillates which contain higher concentrations than the original solutions. This is the basis of their separation from animal tissues for analysis (Heath and Jarvis, 1955), and for some purification procedures (Dutton and Heath, 1956a; Heath and Mattocks, 1961). It follows that vapours above aqueous solutions may contain high concentrations, even though the compounds boil at higher temperatures than water. The 2-hydroxyethyl compounds are miscible with water, from which they are not 
TABLE 1

SOME NITROSAMINES AND THEIR BOILING POINTS AND SOLUBILITIES IN WATER

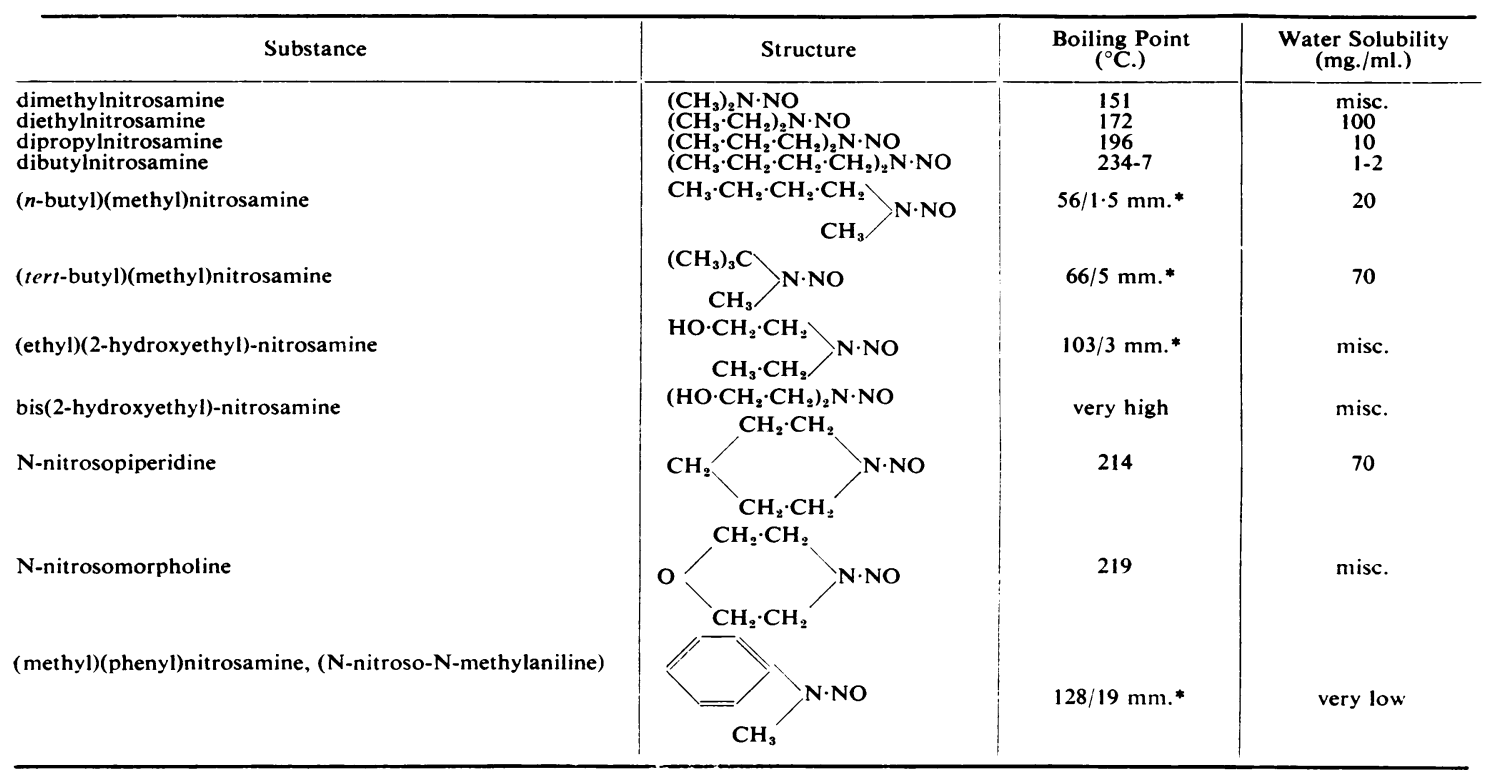

${ }^{*}$ Boiling points at pressures other than atmospheric are given as $x^{\circ} / y \mathrm{~mm}$, i.e. $x^{\circ} \mathrm{C}$. under a pressure of $y$ mm. of mercury.

readily extracted by organic solvents. They are much less volatile, and cannot be distilled from aqueous solutions. $\mathrm{N}$-nitrosomorpholine is intermediate in physical properties between the two groups; and $\mathrm{N}$-nitrosopiperidine resembles diethylnitrosamine rather closely.

Chemically they are stable. They are only hydrolysed slowly by mineral acids at room temperature (rapidly on heating), and too slowly to measure in water and alkaline solution. Bright light decomposes very dilute solutions rapidly, but in intermittent artificial light solutions containing about $50 \mathrm{mg}$./l. of several of the compounds have been stored for several months at $4^{\circ} \mathrm{C}$. without detectable loss.

The combination of high stability with solubility in a wide range of solvents probably explains why the toxicities of several of the compounds are not much dependent on the route of injection. Dimethylnitrosamine, for example, shows the same acute $\mathbf{L D}_{50}$ in rats whether it is given by mouth, intraperitoneally, or intravenously (Barnes and Magee, 1954; Heath, 1962); it is not readily absorbed by the skin.

\section{Toxic Effects}

The toxic effects fall into two main groups: acute effects, which develop within one to two days and, after a lethal dose, usually kill the animal within a week; and carcinogenic effects. Some work has been done on several species (dog, hamster, mouse, rabbit, and rat), and the acute effects are similar in all, except for minor differences in susceptibility. The rat appears to be one of the more resistant species (Barnes and Magee, 1954). In studies on carcinogenity very much more attention has been paid to the rat than to other species, and in this paper observations always refer to the rat unless stated otherwise. There is some evidence of species difference (Magee and Barnes, 1956).

Three acute effects can be distinguished. Only one compound, ( $n$-butyl)(methyl)nitrosamine, has been shown to cause all three.

1. Hepatic centrilobular necrosis. This has been described in several species, and the reader is referred to the original papers for a description (Barnes and Magee, 1954; O'Leary, Wills, Harrison, and Oikemus, 1957; Magee and Barnes, 1956). It is the most typical acute lesion. The doses needed to induce it are listed for several compounds in Table 2. The Table also contains results with three nitrosamines which do not cause this lesion, and with a fourth, bis(2-hydroxyethyl)-nitrosamine, where necrosis may be due to an impurity, as high doses were needed and the compound was hard to purify. As shown later, these exceptions throw some light on the structural requirements for activity in the series. 
TABLE 2

TOXIC EFFECTS OF DIALKYLNITROSAMINES AND RELATED COMPOUNDS

The acute $\mathrm{LD}_{50}$ 's are given, and also the dose, ED, which, given singly, causes distinct hepatic necrosis. Under acute effects the lowest doses which have caused tumours in $50 \%$ of the rats treated are shown, and the organs in which tumours have been found. Note that carcinogenic doses are in $\mathbf{g} . / \mathbf{k g}$. , not $\mathbf{m g} . / \mathrm{kg}$.

\begin{tabular}{|c|c|c|c|c|}
\hline & \multicolumn{2}{|c|}{ Acute Effects } & \multicolumn{2}{|c|}{ Carcinogenic Effects } \\
\hline & $\mathrm{LD}_{\text {so }}$ (mg./kg.) & ED (mg./kg.) & g. $/ \mathbf{k g}$. & Organs Affected \\
\hline $\begin{array}{l}\text { Nitrosamines } \\
\text { dimethyl } \\
\text { diethyl } \\
\text { dipropyl } \\
\text { dibutyl } \\
\text { diamyl } \\
\text { (n-butyl)(methyl) } \\
\text { (tert-butyl)(methyl) } \\
\text { (ethyl)(2-hydroxyethyl) } \\
\text { bis(2-hydroxyethyl) } \\
\text { piperidine } \\
\text { morpholine } \\
\text { (methyl)(phenyl) }\end{array}$ & $\begin{array}{l}27-41\left({ }^{1}, 2\right) \\
216\left({ }^{2}\right) \\
1,750\left({ }^{4}\right) \\
130\left({ }^{2}, ?\right) \\
700(2, ?) \\
- \\
282 \\
200\end{array}$ & $\begin{array}{c}15\left(^{2}\right) \\
130\left({ }^{2}\right) \\
400 \\
800 \\
\left.7 \overline{7},{ }^{2}\right) \\
\text { none at } 1,800\left({ }^{2},{ }^{7}\right) \\
\text { none at } 3,000\left({ }^{2}\right) \\
9,000\left({ }^{2}\right) \\
200 \\
200 \\
\text { none at } 200\end{array}$ & $\begin{array}{c}<0 \cdot 25\left(^{3}\right) \\
0 \cdot 25\left(^{3}\right) \\
2\left({ }^{4}\right) \\
10\left({ }^{5}\right) \\
28(4) \\
0 \cdot 6 \\
- \\
160\left(^{4}\right) \\
2(4) \\
0 \cdot 7\left({ }^{4}\right) \\
\text { none at high doses (4) }\end{array}$ & 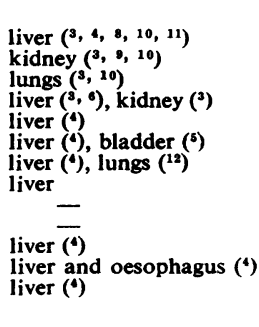 \\
\hline $\begin{array}{l}\text { Formamides } \\
\text { dimethyl } \\
\text { diethyl } \\
\text { ( } \text {-butyl)(methyl) } \\
\text { (tert-butyl)(methyl) }\end{array}$ & $\begin{array}{l}3,800\left(^{2}\right) \\
1,740\left(^{2}\right) \\
\text { c. } 500 \\
\text { c. } 500\end{array}$ & $\begin{array}{l}\text { none } \\
\text { none } \\
\text { none } \\
\text { none }\end{array}$ & $\begin{array}{c}\text { none at } 13\left({ }^{4}\right) \\
\text { - } \\
-\end{array}$ & \\
\hline
\end{tabular}

References: where no reference is given, the figures have not been published elsewhere, and in acute tests the compounds were given intraperitoneally.

(') Barnes and Magee, 1954. ( (2) Heath, 1962. ( ( $\left.{ }^{3}\right)$ Argus and Hoch-Ligeti, 1961. (() Druckrey et al., 1961b. (5) Druckrey, Preussmann, Schmähl, and Müller, 1962. (( $\left.{ }^{\circ}\right)$ Druckrey et al., 1961 c. ( $\left.{ }^{7}\right)$ Heath, 1961. ( ${ }^{8}$ ) Magee and Barnes, 1956. ( $\left.{ }^{(}\right)$Magee and Barnes, 1962. ( $\left.{ }^{10}\right)$ Zak et al., 1960. (11) Schmähl and Preussmann, 1959. (12) Druckrey and Preussmann, 1962.

2. Lesions in other organs, especially in the lung. These are generally observable, though after single doses of dimethyl- and diethylnitrosamine they are slight (Barnes and Magee, 1954; Magee, 1962). The (n-butyl)(methyl) compound causes haemorrhagic lesions in the lungs of rats at $L D_{50}$ doses, and some rats die within a day before the liver lesion is fully developed. Others die two to four days after injection, and in these cases death appears to be more closely correlated with the liver lesion. Acute liver necrosis can, however, be caused by sublethal doses which cause only inconspicuous lung lesions.

3. After high doses of (n-butyl)(methyl)- and (tert-butyl)(methyl)nitrosamines rats suffer mild convulsions, followed by coma, and die quickly, usually within an hour. As the analogous dialkylformamides $\left(\mathrm{CH}_{3} \cdot \mathrm{CH}_{2} \cdot \mathrm{CH}_{2} \cdot \mathrm{CH}_{2}\right)\left(\mathrm{CH}_{3}\right) \mathrm{N} \cdot \mathrm{CHO}$ and $\left[\left(\mathrm{CH}_{3}\right)_{3} \mathrm{C}\right]\left(\mathrm{CH}_{3}\right) \mathrm{N} \cdot \mathrm{CHO}$, cause the same effects at similar doses, probably these effects should be attributed to some biophysical interaction with the nervous system, and will not be considered further.

The carcinogenic effects have been described by numerous authors, and the doses used and the organs affected in rats are listed in Table 2. Tumours have also been found in the trachea and lungs of golden hamsters fed dimethylnitrosamine (Dontenwill and Mohr, 1961). The compounds are remarkably consistent in their action, and it is easy to cause tumours with them in most of a group of animals tested.
Liver tumours are mainly liver cell carcinomas, with or without accompanying fibrosis and cystic bile-duct proliferation. All stages are seen from liver cell adenomas to highly anaplastic hepatocellular carcinomas. Some sarcomas are produced, and very occasionally carcinomas seem to arise from intrahepatic bile-ducts (Argus and HochLigeti, 1961; Magee and Barnes, 1962). Kidney tumours may be either well-differentiated renal adenocarcinomas, often papillary in structure, or undifferentiated. Magee and Barnes (1962) discuss the nature of the latter. In the lung, Zak, Holzner, Singer, and Popper (1960) observed epithelial tumours with alveolar or undifferentiated structures, while Argus and Hoch-Ligeti (1961) observed squamous carcinomas. Oesophageal, bladder, and stomach tumours are all squamous carcinomas.

The main feature in the liver between the necrotic lesion and tumour formation is the development of giant cells with grossly enlarged nuclei. These are conspicuous on histological examination one to two months after the initial dose. Their relation to the other lesions is uncertain (Magee and Barnes, 1956; Christie and Le Page, 1961).

The organs affected depend upon both the dose rates and the strain of rat. Magee and Barnes (1962) showed that when rats were given an $L D_{50}$ dose of dimethylnitrosamine, $15 \%$ of the survivors developed kidney tumours, and that a total dose of about $200 \mathrm{mg} . / \mathrm{kg}$. given over a short period of a few 
weeks caused kidney tumours in over half the treated group. On the other hand, much lower dose rates continued for a period of several months caused liver tumours in nearly all the rats treated, and no kidney tumours (Magee and Barnes, 1956). The effect of dose rate was very marked in this instance. In other rat colonies low dose rates did not give liver tumours only, but about equal numbers of primary liver, lung, and kidney tumours (Argus and Hoch-Ligeti, 1961). These differences did not arise from differences in the total doses given, which were much the same throughout. Diethylnitrosamine has also been studied over a wide range of dose rates (Druckrey, Schmähl and Schildbach, 1961c), but with one exception (Zak et al., 1960) has only been shown to cause liver tumours.

Tumours do not develop only in those organs in which either acute or chronic necrotic damage is most marked. For example, dimethylnitrosamine causes little acute damage to lungs or kidneys, but causes tumours there as readily as in the liver; and diethylnitrosamine caused haemorrhages in lungs, thymus, para-aortic lymph nodes, and gastric mucosa when given over long periods by mouth, but only caused liver tumours (Schmähl, Preussmann, and Hamperl, 1960). These haemorrhagic lesions were not observed in the rats studied by Argus and Hoch-Ligeti (1961).

\section{Toxicity Relationships}

Two relationships are discussed: that between necrotic and carcinogenic activity; and that between toxicity of either kind and chemical structure.

No exact relation can be established between the acute and long-term effects of the compounds because of the difficulties in determining median carcinogenic doses. For example, Druckrey et al. (1961c) dosed rats continuously with various doses of diethylnitrosamine until tumours developed. The relation between total dose given and the dose rate, i.e. the dose given per day, is shown in the Figure. The total dose required increased rapidly with the dose rate. Much of this increase has an obvious explanation: a considerable time elapses between the time when enough damage has been done to make the production of a tumour inevitable and the time when the tumour is first observable as an entity, and all the compound given during this period is excess. The amount of the excess obviously increases with the dose rate. Although, given enough rats, this problem can be overcome, there are other less tractable difficulties. In the case of dimethylnitrosamine in rats, for instance, the relation between dose rate and effective dose is different according to whether kidney or liver tumours are studied. Bear-

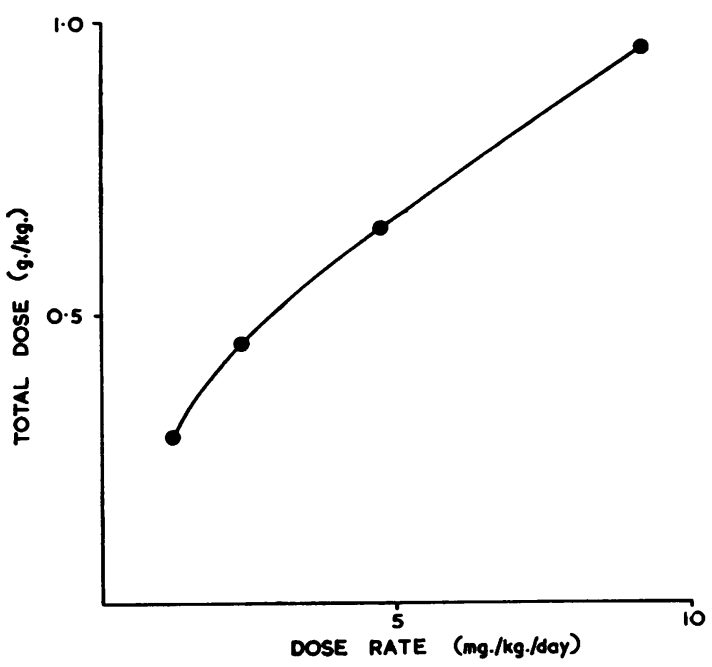

FIGURE Relation between dose rate and total median carcinogenic dose of diethylnitrosamine in rats. (The results are calculated from the Figure given by Druckrey et al., 1961c.)

ing these factors in mind, the following may be stated.

1. In no case have tumours been induced in half of an experimental group by a total divided dose which will not kill more than half the animals by its acute effects if given singly.

2. When the single dose required to cause liver necrosis is under $200 \mathrm{mg}$. $/ \mathrm{kg}$. tumours have been caused by total doses of under $1000 \mathrm{mg} . / \mathrm{kg}$.; when acute effects require 200 to $1000 \mathrm{mg}$. $/ \mathrm{kg}$., tumour formation requires 1 to $10 \mathrm{~g}$. $/ \mathrm{kg}$.; and when acute effects require over $1000 \mathrm{mg} . / \mathrm{kg}$., tumour formation requires over $10 \mathrm{~g} . / \mathrm{kg}$. It appears, therefore, that acute liver necrotic activity and general carcinogenic activity are related in this series of compounds, even though the organs in which tumours develop are not necessarily those in which the necrotic lesions are most pronounced.

It follows that in discussing structure-activity relationships the acute hepatic and long-term effects can be regarded alike; for any compound we can choose whichever effect has been most studied.

1. All the simple dialkylnitrosamines which have been studied are active, and also those with aliphatic nitrogen rings.

2. In those dialkylnitrosamines in which both alkyl groups are the same the activity falls rapidly as the chain length increases. The series has been studied up to diamyl (Druckrey, Preussmann, Schmähl, and Müller, 1961b).

3. Nitrosamines containing 2-hydroxyethyl groups are inactive. In fact, very high doses of the 
bis(2-hydroxyethyl) compound produced tumours (see Table 2), but the authors thought that active impurities might have been present.

4. The introduction of a branched chain greatly decreases the activity. Thus di-isopropylnitrosamine did not show carcinogenic activity at the doses tested, and (methyl)(phenyl)nitrosamine, in which the phenyl group can be regarded as a particular case of a branched chain, was also without activity (Druckrey et al., 1961b).* The effect is shown most clearly by (tert-butyl)(methyl)nitrosamine, which is without necrotic activity although it resembles diethylnitrosamine closely in physical properties (Heath, 1961), and is metabolized in the same way, as described later.

5. Analogues which do not contain the nitrosogroup are without effect. Thus the reduction product of dimethylnitrosamine, dimethylhydrazine, $\left(\mathrm{CH}_{3}\right)_{2} \mathrm{~N} \cdot \mathrm{NH}_{2}$, is without carcinogenic effect (Argus and Hoch-Ligeti, 1961), and the only exception so far found is the oxidation product, dimethylnitramine $\left(\mathrm{CH}_{3}\right)_{2} \mathrm{~N} \cdot \mathrm{NO}_{2}$, which causes some kidney tumours and no liver tumours, in rats given a total dose of $40 \mathrm{~g} . / \mathrm{kg}$. (Druckrey et al., 1961b). The possibility that dimethylnitrosamine is formed by metabolic reduction has not been ruled out.

Of particular interest are the dialkylformamides. These are very similar in structure and physical properties to the analogous nitrosamines. Dimethylformamide is of very low toxicity to rats when given as a $50 \%$ solution in normal saline (see Table 2), and can be used as a vehicle for the injection of compounds insoluble in water. It is a little more toxic to mice $(1560 \mathrm{mg} . / \mathrm{kg}$. intraperitoneally). These results contradict those of Massmann (1956), who claimed very much higher toxicities. Smyth and Carpenter (1948), however, found that dimethylformamide was less toxic orally in rats than Massmann did, and Davis and Jenner (1959) found its intraperitoneal $\mathrm{LD}_{50}$ in mice was $1122 \mathrm{mg} . / \mathrm{kg}$., not much less than our value. Diethylformamide is more toxic to rats, and ( $n$-butyl)(methyl)- and (tertbutyl)(methyl)-formamides considerably more toxic. None, however, produces centrilobular necrosis at lethal doses. Dimethylformamide causes some periportal damage, which is easily distinguished.

\section{Metabolism}

Only dimethylnitrosamine has been studied in vitro. It is decomposed by liver slices and by liver microsomes plus cell sap. Nicotinamide-adenine dinucleotide phosphate (triphosphopyridine nucleo-

*(Methyl)(phenyl)nitrosamine can cause oesophageal tumours when
given orally in high doses (Druckrey, Preussmann, Schmähl, and Blum, 1961a). The local exposure may be very great in this case. tide) and oxygen are needed, and the rate of decomposition is reduced by SKF 525A, an inhibitor of microsomal oxidative enzymes. One of the products is formaldehyde (Magee and Vandekar, 1958; Brouwers and Emmelot, 1960). It is concluded that the compound is decomposed by enzymic oxidation, and that the enzymes are similar to those studied by Axelrod, Reichenthal, and Brodie (1954). Brouwers and Emmelot (1960) also showed that hepatic tumours had little capacity to oxidize the compound; and Magee and Vandekar (1958) that kidney, spleen, and lung preparations had also little or no capacity.

Much more extensive studies have been carried out in vivo, in attempts to explain the action of the compounds. Magee (1956) concluded from the high rate of disappearance of dimethylnitrosamine from rats and rabbits that dimethylnitrosamine was decomposed rapidly, as very little was excreted in the urine. This conclusion was confirmed by Dutton and Heath (1956b), who showed that $60 \%$ of the ${ }^{14} \mathrm{C}$ given as $\left[{ }^{14} \mathrm{C}\right]$ dimethylnitrosamine to rats was expired as ${ }^{14} \mathrm{CO}_{2}$ in a few hours. Magee also showed that total hepatectomy reduced the rate of disappearance almost to zero in rats, while nephrectomy was without effect; and that in mice, SKF 525A also reduced the rate of disappearance. Thus, decomposition in vivo resembles decompostion in vitro closely, and is practically confined to the liver. As this is the only organ that undergoes severe necrosis, it was concluded that the toxic agent was a metabolite. This conclusion has been confirmed by a recent investigation (Heath, 1962). Dimethyl-, diethyl-, (n-butyl)(methyl)- and (tert-butyl)(methyl)nitrosamines were prepared labelled in their methyl, ethyl, n-butyl, and tert-butyl groups (Heath and Mattocks, 1961). All four compounds were rapidly decomposed, as shown by ${ }^{14} \mathrm{CO}_{2}$ expiration, and were only excreted in the urine or in the expired air to a small extent. The action of inhibitors of oxidation was also studied, and this was correlated with their effects on acute toxicity. The only simple explanation of the results was provided by the following reaction scheme, in which dimethylnitrosamine is taken as an example.

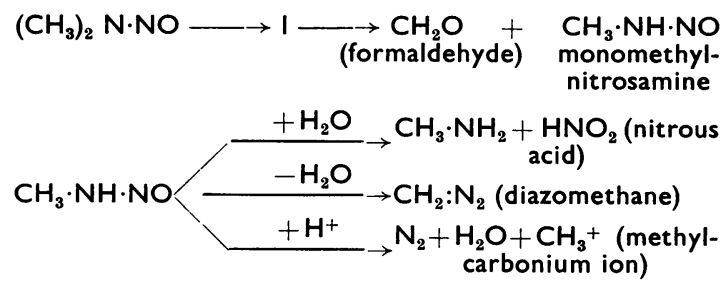

In the first stage the nitrosamine is oxidized to formaldehyde and monomethylnitrosamine, via 
non-toxic intermediates. Monomethylnitrosamine then decomposes spontaneously and very rapidly, in part to nitrite and methylamine (Heath and Dutton, 1958), but also to diazomethane and/or carbonium ions. The toxic action must be attributed either to diazomethane, as suggested by Rose (1958) and R. Schoental (personal communication), or to monomethylnitrosamine acting through the release of carbonium ions. The toxic metabolites are both powerful alkylating agents. Either hypothesis can explain the lack of activity in (tert-kutyl)(methyl)and (methyl)(phenyl)-nitrosamines.

The work also suggested a reason for the lack of activity in (2-hydroxyethyl)nitrosamines. The two tested were only weak inhibitors of the oxidation of dimethylnitrosamine, and probably they are too insoluble in fat to be oxidized, but are excreted instead.

\section{Biochemical Effects}

Both in vivo (Emmelot and Mizrahi, 1961; Magee, 1958) and in vitro (Brouwers and Emmelot, 1960; Hultin, Arrhenius, Löw, and Magee, 1960) dimethylnitrosamine inhibits protein synthesis in the liver as measured by the incorporation of ${ }^{14} \mathrm{C}$-labelled amino acids. Protein synthesis was also inhibited in microsomal preparations from poisoned rats (Hultin et al., 1960). The inhibition appears to be due to a metabolite. Thus inhibition increased with the time the liver was exposed to the nitrosamine, and was marked after one hour's exposure in vitro and three hours' in vivo. Protein synthesis was very little inhibited in hepatic tumour tissue, which has little capacity to oxidize dimethylnitrosamine (Brouwers and Emmelot, 1960); and inhibition was slight in rats pretreated with high doses of cysteine, which may be expected to react with several of the possible metabolites, but not with dimethylnitrosamine itself (Emmelot and Mizrahi, 1961).

Dimethylnitrosamine also alters normal metabolism by reducing the incorporation of ${ }^{32} \mathrm{P}$ into RNA phosphorus (Magee, 1958) and the incorporation of adenine into nucleic acids (Hultin et al., 1960). No other metabolic disturbances have been found until liver damage is marked (Magee, 1958; Bailie and Christie, 1959; Hultin et al., 1960). At this stage they may be secondary.

\section{Alkylation of Ribonucleic Acid and Proteins}

In rats, both liver ribonucleic acid (Magee and Farber, 1962) and liver protein (Magee and Hultin, 1962) are methylated by dimethylnitrosamine. In ribonucleic acid, guanine residues are methylated in the 7-position, giving a ribonucleic acid which is not a normal constituent. Magee and Farber (1962) showed that ribonucleic acid is also methylated to some extent in the kidney (confirming that the kidney has a slight capacity to oxidize dimethylnitrosamine); and diethylnitrosamine probably also produces 7-ethylguanine in the liver (Magee, unpublished data).

\section{Therapy}

High and barely tolerable doses of cysteine given prophylactically over two days about doubled the resistance of rats to dimethylnitrosamine (Emmelot and Mizrahi, 1961). No other treatment has been found which has a marked effect on toxicity.

Any chemical therapy will probably have both to be applied very shortly after the uptake of the nitrosamine, as this is decomposed rapidly to toxic products; and also to protect the animal against the toxic products either by combining with them or in some other way. Inhibitors of decomposition have very little effect (Heath, 1962), and what there is can be wholly accounted for by the higher proportion of the nitrosamine excreted in urine and expired air when its persistence in vivo is increased.

\section{Discussion}

The high acute toxicities and carcinogenic activities of several nitrosamines are well established, and the main structural requirements are known, though later work may lead to some modifications. It is known that several compounds are mainly disposed of in the body by oxidation, and not by excretion, though the 2-hydroxyethyl compounds are probably exceptions to this rule.

The compounds causing acute necrosis are metabolites, and are probably alkylating agents, either diazoalkanes or carbonium ions. As diazomethane is carcinogenic (Schoental, 1960; Schoental and Magee, 1962) and mutagenic (Westergaard, 1957), it is tempting to assume that the carcinogenic action of the compounds should be attributed to the same metabolites. This fits in with the observed mutagenic effects of dimethyl sulphate on tobacco mosaic virus (Fraenkel-Conrat, 1961), and to the explanations of such effects discussed by Brookes and Lawley (1961 a and b). There are, however, three objections to this.

1. It is likely that nitrite is released, and this has been found to be more mutagenic on tobacco mosaic virus than any alkylating agent tried (Fraenkel-Conrat, 1961). Mutagenicity and carcinogenicity are not, of course, inevitably correlated.

2. Although median carcinogenic doses are not known accurately, dimethyl- and diethylnitrosamines have been investigated fully enough for it to be clear that their median carcinogenic 
doses are fairly close; but diethylnitrosamine has only about one-tenth the necrotic action of dimethylnitrosamine. If it is allowed that most of the other carcinogenic doses given in Table 2 are too high, then there are probably other similar anomalies. This may not imply that the metabolite is different; the different effects may be caused in each case by the same metabolite acting on different biochemical systems.

3. The alkylating agents postulated are exceedingly unstable, and it seems unlikely that significant amounts could survive passage in the blood stream from organ to organ. Yet dimethylnitrosamine causes tumours in organs in which oxidation only takes place slowly, and which show little acute damage.

The carcinogenic compound is still, therefore, in doubt. It is therefore at least possible either that the toxic metabolite reacts with some normal liver constituent to give a more stable compound which is carcinogenic, or that the processes of repair in a damaged liver themselves produce a carcinogen.

The particular hazard from the nitrosamines is their "one-shot" carcinogenic effect. If man is like the rat in his response, not only long-term exposure but also a single serious incident may give rise to unpleasant sequelae years later. This feature of their toxic action should be considered if nitrosamines are to be used industrially.

\section{REFERENCES}

Argus, M. F., and Hoch-Ligeti, C. (1961). J. nat. Cancer Inst., 27, 695.
Axelrod, J., Reichenthal, J., and Brodie, B. B. (1954). J. Pharm. exp. Ther., 112, 49.

Bailie, M. J., and Christie, G. S. (1959). Biochem. J., 72, 473.

Barnes, J. M., and Magee, P. N. (1954). Brit. J. industr. Med., 11, 167. Brookes, P., and Lawley, P. D. (1961a). J. chem. Soc., p. 3923

Brookes, P., and Lawley, P. D. (1961 b). Biochem. 80,496

Brouwers, J. A. J., and Emmelot, P. (1960). Exp. Cell Res., 19, 467.

Christie, G. S., and Le Page, R. N. (1961). Lab. Invest., 10, 729.

Davis, K. J., and Jenner, P. M. (1959). Toxicol. appl. Pharmacol., $1,576$.

Dontenwill, W., and Mohr, U. (1961). Klin. Wschr., 39, 493.

Druckrey, H., and Preussmann, R. (1962). Naturwissenschaften, 49, 111 .

,$- \frac{1}{-}$, Schmähl, D., and Blum, G. (1961 a). ibid., 48, 722.

,,-- , and Müller, M. (1961b). ibid., 48, 134.

-,, , (1962). ibid., 49, 19.

(1961) 56

Dutton, A. H., and Heath, D. F. (1956a). J. chem. Soc., p. 1892.

- (1956b). Nature (Lond.), 178, 644.

Emmelot, P., and Mizrahi, I. J. (1961). ibid., 192, 42

Fraenkel-Conrat, H. (1961). Biochim. biophys. Acta (Amst.), 49, 169. Heath, D. F. (1961). Nature (Lond.), 192, 170. (1962). Biochem. J., 85, 72.

, and Dutton, A. (1958). ibid., 70, 619.

, and Jarvis, J. A. E. (1955). Analyst, 80, 613.

, and Mattocks, A. R. (1961). J. chem. Soc., p. 4226.

Hultin, T., Arrhenius, E., Löw, H., and Magee, P. N. (1960). Biochem. J., 76, 109.

Magee, P. N. (1956) ibid, 64, 676.

Magee, P. N. (1956). ibid., 70, 606 .

(1958). ibid., 70, 606.

(1962). The Scientific Basis of Medicine, Annual Reviews, p. 172.
British Postgraduate Medical Federation, University of London, Athlone Press.

-, and Barnes, J. M. (1956). Brit. J. Cancer, 10, 114

, (1962). J. Path. Bact., 84, 19.

, and Farber, E. (1962). Biochem. J., 83, 114.

, and Hultin, T. (1962), ibid., 83, 106.

Massmann, W. (1956). Brit. J. industr. Med., 13, 51.

Massmann, W. (1956). Brit. J. industr. Med., 13, 51. Proc. Soc. exp. Biol. (N.Y.), 94, 775.'

Proc. Soc. exp. Biol. (N.Y.), 94, 775.
Reilly, E. L. (1961). British Patent, No. 867,992.

Rose, F. L. (1958). In A Symposium on the Evaluation of Drug Toxicity, ed. A. L. Walpole and A. Spinks, p. 116. Churchill, London.

Schmähl, D., and Preussmann, R. (1959). Naturwissenschaften. 46, 175.

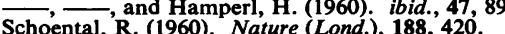

tal, R. (1960). Nature (Lond.), 188, 420.

- Brit. J. Cancer, 16, 92.

Smyth, H. F., and Carpenter, C. P. (1948). J. industr. Hyg., 30, 63.

Weil, C. S. (1952). Biometrics, 8,3

Westergaard, M. (1957). Experientia (Basel), 13, 224

Zak, F. G., Holzner, J. H., Singer, E. J., and Popper, H. (1960). Cancer Res., 20, 96. 